\title{
A PARTICIPAÇÃO DAS VÍTIMAS NOS JULGAMENTOS DO TRIBUNAL PENAL INTERNACIONAL
}

\author{
VICTIM PARTICIPATION ON \\ INTERNATIONAL CRIMINAL COURT TRIALS
}

\author{
BIANCA FRANCO DA ROSA GUIMARÃES ${ }^{1}$ \\ JOÃO IRINEU DE RESENDE MIRANDA ${ }^{2}$
}

\begin{abstract}
RESUMO: Este artigo busca analisar o papel das vítimas dentro procedimento criminal previsto pelo Estatuto de Roma, tratado que criou e regulamenta o Tribunal Penal Internacional. Para tanto apresenta a contribuição do Estatuto de Roma para a determinação do indivíduo como Sujeito dotado de personalidade jurídica internacional e analisa as dificuldades práticas referentes à participação das vítimas dentro dos procedimentos criminais internacionais. Dentre os resultados obtidos percebe-se que uma maior aproximação com as vítimas pode contribuir para reforçar a legitimidade do Tribunal perante as sociedades atingidas pelos crimes. Contudo, conclui-se que as expectativas das vítimas com os julgamentos dificilmente serão atingidas fora de um contexto mais amplo em que exista a aplicação dos postulados da justiça de transição.

PALAVRAS-CHAVE: Tribunal Penal Internacional; Justiça de Transição; Processo Penal Internacional.
\end{abstract}

\begin{abstract}
This article seeks to analyze the victim's role in the procedures at the international criminal court. To achieve that, it presents the Rome Statute's contribution on the matter, regarding the individual as subject of the international law. In addition, it shows the pratical issues inherent to the victim's actions on the criminal procedure. The article concludes that the victim's participation on the process could legitimize an international judgment at the ICC it the tribunal becomes closer to the afflicted local communities. On the other hand, the victim's expectations won't be satisfied unless their role on the criminal procedure have been subject to reparation measures at the transitional justice enviroment.

KEYWORDS: International Criminal Court; Transitional Justice; International Criminal Procedure.
\end{abstract}

\footnotetext{
Artigo recebido em 25.07.2012. Pareceres emitidos em 19.08.2012 e 14.09.2012.

Artigo aceito para publicação em 19.11.2012.

${ }^{1}$ Graduanda do Curso de Direito da Universidade Estadual de Ponta Grossa - Paraná, pesquisadora do Grupo de Pesquisa em Direito Internacional Penal da Universidade Estadual de Ponta Grossa. bianca_frg@hotmail.com

${ }^{2}$ Professor do Curso de Direito da Universidade Estadual de Ponta Grossa - Paraná, Doutor em Direito Internacional pela Faculdade de Direito da USP, coordenador do Grupo de Pesquisa em Direito Internacional Penal da Universidade Estadual de Ponta Grossa. joaoirineu@uepg.br
} 
SUMÁRIO: Introdução; 1. Tribunal Penal Internacional: breves noções; 2. O Surgimento de Novos Sujeitos de Direito Internacional; 3. Dificuldades Práticas; 4. Justiça de Transição; Considerações Finais; Referências.

SUMMARY: Introduction; 1 . International Criminal Court: brief notions; 2 . The Emergence of New Subjects to International Law; 3. Practical Difficulties; 4. Transitional Justice; Final Thoughts; References.

\section{INTRODUÇÃO}

O Tribunal Penal Internacional trouxe uma série de inovações ao Direito Internacional que ainda não foram completamente analisadas pela doutrina ou aplicadas pela jurisprudência. Dentre elas destaca-se a possibilidade das vítimas participarem do procedimento criminal internacional juntamente com o Procurador. Tal participação levanta questões tanto na seara do Direito Processual Penal quanto na seara dos Direitos Humanos. Destacam-se, entretanto, as observações levantadas pelas próprias vítimas que tem participado dos procedimentos criminais através de seus advogados. Seus relatos parecem indicar um hiato entre as expectativas das vítimas pelo reconhecimento do que sofreram e pela reparação do mal ao qual foram submetidas e o papel que lhes cabe dentro do procedimento criminal, nos termos propostos pelo Estatuto de Roma (tratado que criou e que regulamenta o Tribunal Penal Internacional) e pelas Regras de Procedimento e Prova do Tribunal.

Seria a participação das vítimas nos procedimentos o caminho mais adequado para atender suas expectativas? Para responder esta pergunta este artigo tomará por base a transcrição dos relatos de vítimas de crimes em julgamento pelo Tribunal Penal Internacional, realizando uma pesquisa bibliográfica norteada pelo método indutivo, pois as visões localizadas dos indivíduos servirão como base para analisar-se um instituto de aplicação geral.

Deste modo, na primeira seção serão apresentadas breves noções acerca do Tribunal Penal Internacional, evidenciando-se a participação dos indivíduos no polo ativo do processo, tema que será desdobrado na segunda seção, relativa ao surgimento de novos sujeitos de Direito Internacional. As dificuldades práticas advindas da participação das vítimas no procedimento criminal serão tratadas na terceira seção. Por fim, a justiça de transição, tema obrigatório quando se trata de medidas relativas ao direito à memória e à reparação, será tratada na última seção, na qual será feita a análise do Caso Lubanga, até agora o único concluído pelo Tribunal Penal Internacional.

\section{TRIBUNAL PENAL INTERNACIONAL: BREVES NOÇÕES}

O Tribunal Penal Internacional, instância internacional de julgamento de caráter permanente representa uma das facetas da consolidação de uma nova ordem internacional, na qual a proteção dos direitos humanos é valor fundamental. Não surgiu de repente, mas em razão do sentimento de 
indignação da comunidade global que girava em torno da questão da efetiva defesa dos direitos humanos. ${ }^{3}$

É a primeira corte de julgamento que tem caráter permanente, ao contrário dos outros tribunais constituídos anteriormente na história para julgar crimes internacionais, caso, por exemplo, dos tribunais de Nuremberg (1945/1946) e Tóquio (1946/1948), que, não obstante tenham sido amplamente criticados no que se refere aos critérios políticos de julgamento, bem como à lesão a vários princípios do Direito Penal, como o da legalidade, deixaram um legado positivo para o Direito Internacional Penal ${ }^{4}$, pois alimentaram a esperança de que, no futuro, os crimes contra os direitos humanos fossem julgados em um tribunal penal permanente, imparcial e independente. ${ }^{5}$

A instituição dos Tribunais ad hoc para a ex-luguslávia em 1993 e Ruanda (1994) pela iniciativa do Conselho de Segurança da ONU também foram demonstrações de que, por vezes, os governos não eram capazes de julgar violadores de direitos humanos, na medida em que não puniam os responsáveis pelas atrocidades cometidas em seus territórios. ${ }^{6}$ Tais tribunais foram alvo de diversas críticas, assim como os supracitados. Todavia, contribuíram para que se tornasse patente o vazio jurídico decorrente da inexistência de uma jurisdição penal internacional, cuja percepção culminou no surgimento do Tribunal Penal Internacional.

Esta corte foi criada pelo Estatuto de Roma, tratado multilateral, que após ter enfrentado grandes dificuldades de consenso relativamente ao seu texto, entrou em vigor em $1^{\circ}$ de julho de 2002, quando contou com as 60 ratificações necessárias, conforme dispõe seu artigo 126. No Brasil passou a vigorar em $1^{\circ}$ de setembro do mesmo ano, a partir da promulgação do Decreto $n^{\circ} 4.388 / 02$, que o incorporou na ordem jurídica brasileira.

Tem como um de seus princípios a complementaridade de jurisdição, ou seja, ele atuará nas situações mais graves, em que se verifique a incapacidade ou falta de disposição dos Estados-parte de processar os responsáveis pelos crimes nele previstos, considerados os de maior gravidade com alcance internacional, quais sejam, genocídio, crimes contra a humanidade, crimes de guerra e de agressão.

Na data de elaboração deste trabalho, onze casos estão sendo analisados perante o Tribunal Penal Internacional, e 119 países são Estados-parte: 33 Africanos, 17 localizados na Ásia/pacífico, 18 da Europa Oriental, 26 da América latina e 25 da Europa Ocidental e outros países. Nos termos do Estatuto,

\footnotetext{
${ }^{3}$ LIMA, Renata Mantovani de; BRINA, Marina Martins da Costa. Para Entender o Tribunal Penal Internacional. Belo Horizonte: Del Rey, 2006, p. 41.

${ }^{4}$ MIRANDA, João Irineu de Resende. O Tribunal Penal Internacional frente ao Princípio da Soberania. Londrina: Eduel, 2011, p. 55.

${ }^{5}$ MAIA, Marrielle. Tribunal Penal Internacional: aspectos institucionais, jurisdição e princípio da complementaridade. Belo Horizonte: Del Rey, 2001, p. 50.

${ }^{6}$ Ibid., p. 53.
} 
o Promotor pode iniciar uma investigação com base em acionamentos a partir de qualquer Estado Parte ou do Conselho de Segurança da ONU, além de poder iniciá-las ex officio com base em informações provenientes de indivíduos ou organizações (comunicações). ${ }^{7}$

Até o momento, três Estados-partes - Uganda, República Democrática do Congo e República Centro-Africana - encaminharam casos que ocorreram em seus territórios. Além disso, o Conselho de Segurança remeteu ao Promotor a situação de Darfur, no Sudão e da Líbia - ambos Estados que não são partes no Estatuto de Roma. ${ }^{8}$ Ressalte-se que, quando é o referido conselho que aciona a jurisdição do Tribunal, não importa se o Estado em questão é ou não signatário. ${ }^{9} \mathrm{O}$ promotor está conduzindo investigações em todos estes casos acima mencionados. Ademais, as Câmaras de Questões Preliminares também autorizaram que fossem abertas investigações no Quênia e na Costa do Marfim. ${ }^{10}$

O procedimento de persecução penal do Tribunal Penal Internacional não tem natureza pura, não sendo puramente acusatório, pois existem elementos inquisitórios incorporados no Estatuto de Roma e no seu Regulamento Processual, os quais foram inseridos para atender aos países que seguem esse sistema. ${ }^{11}$

Não bastasse toda a novidade que representa essa corte de julgamento, o Tribunal Penal Internacional traz outros dispositivos inovadores, como as previsões que privilegiam os direitos das vítimas no processo. O artigo 75 do Estatuto de Roma é um deles, e prevê a possibilidade de que vítimas dos crimes sob julgamento possam pleitear reparação, que poderá assumir a forma de restituição, indenização ou reabilitação.

Também relativamente ao direito de vítimas, o art. 68 (3) do mencionado estatuto prescreve:

3. Se os interesses pessoais das vítimas forem afetados, o Tribunal permitir-Ihes-á que expressem as suas opiniões e preocupações em fase processual que entenda apropriada e por forma a não prejudicar os direitos do acusado nem a ser incompatível com estes ou com a realização de um julgamento eqüitativo e imparcial. Os representantes legais das vítimas poderão apresentar as referidas opiniões e preocupações quando o Tribunal o considerar oportuno e em conformidade com 0 Regulamento Processual.

\footnotetext{
${ }^{7}$ INTERNATIONAL CRIMINAL COURT - The States Parties to the Rome Statute. Disponível em: <http://www.icc cpi.int/Menus/ASP/states+parties/ > Acesso em 03 nov. 2011.

${ }^{8}$ INTERNATIONAL CRIMINAL COURT - The States Parties to the Rome Statute. Disponível em: $<$ http://www.icc cpi.int/Menus/ASP/states+parties/ > Acesso em 03 nov. 2011.

${ }^{9}$ LIMA, Op. Cit., p. 71.

${ }^{10}$ INTERNATIONAL CRIMINAL COURT - The States Parties to the Rome Statute. Disponível em: <http://www.icc cpi.int/Menus/ASP/states+parties/ > Acesso em 03 nov. 2011.

11 ZAPPALÀ, Salvatore. The Rights of Victims v. the Rights of the Accused. Journal of International Criminal Justice (Oxford University Press) Vol. 8, 2010, p. 162.
} 
Tal dispositivo recebeu diversas críticas por parte da doutrina, dentre as quais destaque-se a alegação relativa à possibilidade de violação aos direitos do acusado. De acordo com o texto do Estatuto de Roma, os direitos do acusado devem ter primazia, o que não significa, todavia, que as vítimas não possam ter possibilidade de agir processualmente também. Sendo assim, esses direitos devem ser exercidos de forma que não prejudique as prerrogativas do acusado e que não seja incompatível com a realização de um julgamento equitativo e imparcial, pois toda a legitimidade do julgamento está pautada no respeito aos direitos do acusado, não existindo verdade que possa ser alcançada sem o respeito ao devido processo legal. ${ }^{12}$ Neste ínterim, podemos lembrar o exemplo clássico a não ser seguido do julgamento de Adolf Eichmann. ${ }^{13}$

Alguns afirmam também que dando às vítimas o direito de participação, abalar-se-ia o princípio da paridade de armas. Entretanto, esse argumento é rebatido tendo em vista que as vítimas não são partes, são participantes. ${ }^{14}$ Caso contrário, teria o acusado que se defender de mais uma parte, o que não é verdadeiro. Da mesma forma, é alegado também que a participação das vítimas poderia ferir a presunção de inocência e diminuir a imparcialidade do tribunal. No entanto, os juízes devem se basear nos princípios do estatuto, dando primazia aos direitos do acusado, tendo em vista que o próprio artigo 68 prescreve que a participação deve se dar de maneira não prejudicial.

\section{O SURGIMENTO DE NOVOS SUJEITOS DE DIREITO INTERNACIONAL}

O processo cada vez mais acentuado de universalização dos direitos humanos traz como consequência a possibilidade de concretização dos suprarreferidos direitos de participação das vítimas previstos pelo Estatuto de Roma, considerando que a existência de tais prescrições somente foi possível a partir do reconhecimento de direitos da pessoa física em âmbito internacional.

$\mathrm{Na}$ nova ordem internacional, segundo o dizer de Cançado Trindade: "Não se pode visualizar a humanidade como sujeito de Direito a partir da ótica do Estado, impõe-se reconhecer os limites do Estado a partir da ótica da humanidade". ${ }^{15}$

\footnotetext{
${ }^{12}$ ZAPPALÀ, Op. Cit, p. 144-145.

${ }^{13}$ Karl Adolf Eichmann foi o grande responsável pela logística de extermínio de milhões de pessoas durante o Holocausto, na Segunda Guerra Mundial. Em 1960, foi raptado por uma equipe de agentes secretos israelitas na Argentina, após meses de observação, e foi então levado para julgamento em Israel. O julgamento causou grande controvérsia internacional, tendo sido permeado por diversas irregularidades jurídico-formais.

${ }^{14}$ FRIMAN, Hãkan. The International Criminal Court and Participation of Victims: A Third Party to the proceedings? Leiden Journal of International Law (Foundation of the Leiden Journal of international Law), vol. 22, 2009, p. 500.

15 TRINDADE, Antônio Augusto Cançado; ROBLES, Manuel E. Ventura. El futuro de La Corte Interamericana de Derechos Humanos, p. 206, apud PIOVESAN, Flávia. Direitos Humanos e Justiça Internacional: um estudo comparado dos sistemas regionais europeu, interamericano e africano. São Paulo: Saraiva, 2006, p. 12.
} 
Sendo assim, com o fortalecimento desta ideia cristaliza-se o entendimento de que o indivíduo deve ter direitos protegidos na esfera internacional, na condição de sujeito de direitos, o que também demonstra que prenuncia-se o fim da era em que a forma pela qual o Estado trata seus nacionais seja um problema de jurisdição doméstica, pois o processo de universalização dos direitos humanos impõe que o problema concernente à relação entre governante e governados seja suscetível de preocupação de toda a comunidade internacional. ${ }^{16}$

Este é o contexto da criação de uma sociedade civil globalizada ${ }^{17}$, que tem como atores além dos Estados, as Organizações Internacionais Governamentais, Organizações não Governamentais, bem como as pessoas físicas. Esta nova configuração do cenário internacional demandou a transição da ideia westfaliana de soberania estatal absoluta, pela qual entendia-se que o Estado era o sujeito principal e único na esfera transnacional e os indivíduos seriam detentores de direitos tão somente em âmbito nacional. Nesta conjuntura, a pessoa que tivesse sofrido danos por outro Estado que não o de sua nacionalidade poderia apenas pedir indenizações por meio do Estado a que pertencia. Além disso, muitos países se fiavam na tradicional doutrina de soberania para se opor à responsabilização de seus atos. ${ }^{18}$

O Tribunal Penal Internacional representa uma das faces dessa emergente ordem internacional, que dá primazia à pessoa humana e traz consigo a possibilidade de que sejam responsabilizados os perpetradores dos mais graves crimes, que são aqueles que geralmente gozam de imunidade internacional por serem agentes políticos que utilizam a máquina estatal para o alcance de seus propósitos e acabavam se furtando de suas responsabilidades por privilégios concedidos pelo correspondente ordenamento jurídico pátrio. ${ }^{19}$

Destarte, configura-se a concretização de uma forma de jurisdição chamada de jurisdição universal, que poderá investigar e processar uma pessoa suspeita de cometer um crime em qualquer lugar do mundo, independentemente de sua nacionalidade e de ligação com o país em que o Tribunal está localizado. Os crimes tipificados pelo Estatuto de Roma são tão graves que equivalem a crimes contra toda a humanidade e, portanto, todos os Estados têm a responsabilidade de levar os responsáveis à justiça. Este ponto de vista é ilustrado já no preâmbulo do Estatuto de Roma. ${ }^{20}$

Com isso, os tratados internacionais deixam de ser aplicáveis apenas na relação entre indivíduo-estado, sendo passíveis de aplicação, do mesmo modo,

\footnotetext{
${ }^{16}$ PIOVESAN, Loc. Cit.

17 GLASIUS, Marlies. What is Global Justice and Who Decides? Civil Society and Victim Responses to the International Criminal Court's First Investigations. Human Rights Quarterly, The Johns Hopkins University Press, v. 31, nº 2, maio de 2009, p. 497.

${ }^{18}$ BASSIOUNI, M. Cherif, International Recognition of Victims' Rights. Human Rights Law Review. Oxford University Press, v. 6, $\mathrm{n}^{\circ} 2,2006$, p. 212-213.

${ }^{19}$ LIMA, Op. Cit., p. 174.

${ }^{20}$ BASSIOUNI, Op. Cit., p. 232.
} 
entre indivíduos. Assim, o agressor não é apenas responsável criminalmente pelos delitos que cometeu em relação à comunidade internacional, mas o é também pelos danos que causou às vítimas que são objeto de proteção das normas penais. O princípio de que indivíduos são obrigados a pagar indenização pelos danos que causou é visto agora como um princípio geral de direito. ${ }^{21}$

Já desde a confecção do Estatuto teve a sociedade civil uma atuação marcante, caracterizada pela influência das ONGs na redação de alguns dispositivos. Estas organizações tem um papel vital no que concerne à matéria de proteção e promoção dos direitos humanos, considerando que dentre as suas funções está a de criar uma sensibilização, por meio da disseminação de informação e educação de valores relativos aos referidos direitos. A Coalizão pelo Tribunal Penal Internacional (Coalition for the International Criminal Court) ${ }^{22}$, por exemplo, através de redes, divulgação de informações e construção de coligações, desenvolveu um papel relevante no desenvolvimento do projeto do Estatuto. ${ }^{23}$

Neste contexto, a ONG Women Caucus for Gender Justice também pode ser citada por ter trazido à tona as questões que não estavam sendo adequadamente discutidas durante as negociações, relativas à inclusão de crimes de gênero no estatuto e a medidas especiais de proteção para vítimas de violência sexual. ${ }^{24}$ Desta forma, as regras do Tribunal Penal Internacional asseguram o tratamento da perspectiva de gênero, reconhecendo três princípios importantes no tocante às vítimas e testemunhas: sua participação no processo, proteção e direito à reparação, o que é particularmente importante para mulheres, que podem ser provenientes de países onde os crimes de violência sexual podem as tornar impuras ou ostracizá-las de sua comunidade. $^{25}$

O direito de participação das vítimas no procedimento penal também teve sua inclusão no texto do Estatuto influenciada pela motivação da sociedade civil. Entretanto, na condição de assistentes de acusação as vítimas terão direitos limitados, pois terão possibilidade apenas de expor suas visões e tentar persuadir a Câmara desde que, como já mencionado, esses atos não sejam incompatíveis com a realização de um julgamento equitativo e imparcial.

\footnotetext{
21 ZEGVELD, Liesbeth. Victims' Reparations Claims and International Criminal CourtIncompatibleValues? Journal of International Criminal Justice, Oxford University Press, v. 8, 2010, p. 85.

${ }^{22}$ A CICC inclui 2.500 organizações da sociedade civil em 150 países diferentes, e trabalha em parceria para fortalecer a cooperação internacional com o TPI. COALITION FOR THE INTERNATIONAL CRIMINAL COURT. About The Coalition. Disponível em: <www.iccnow.org>. Acesso em: 18 out. 2011.

${ }^{23}$ VYVER, Johan D. Van Der. Civil Society and the International Criminal Court. Journal of Human Rights, vol. 2, n 3, set. 2003, p. 426-427.

${ }_{24}$ JOSEPH, Joshua H. Gender and International Law: How the Internacional Criminal Court can bring justice to victims of sexual violence. Texas Journal of Women and the Law (University of Texas at Austin School of Law Publications) Vol. 18:61, 2008, p. 65.

${ }^{25}$ Ibid., p. 97.
} 
A matéria relativa à participação das vítimas é regulada a partir da regra $n^{\circ} 85$ das Regras de Procedimento e Provas do Tribunal Penal Internacional (RPE). De acordo com este diploma:

(a) por "vítimas" entender-se-ão as pessoas naturais que tenham sofrido um dano como conseqüência do cometimento de algum crime da competência do Tribunal;

(b) por vítimas poder-se-ão entender também as organizações ou instituições que tenham sofrido danos diretos a algum de seus bens que esteja dedicado à religião, à instrução, às artes, às ciências ou à beneficência, e a seus monumentos históricos, hospitais e outros lugares e objetos que tenham fins humanitários.

Todavia, pode-se perceber que este regramento não esclarece de forma exaustiva quais são as pessoas que poderão receber a qualificação de vítima, pois, em se tratando das pessoas naturais, não há definição do dano, não restando claro se é necessário que o mesmo tenha que ter sido sofrido de forma direta ou indireta, ficando obscura a questão do nexo de causalidade exigido para que o indivíduo tenha ou não o direito de participação. Há que se ressaltar que os crimes que serão julgados por essa Corte serão complexos e de grande magnitude, podendo afetar número inimaginável de pessoas. Com essas previsões lacunosas, não se pode afirmar se as pessoas que foram atingidas pelos crimes que não sejam aqueles tipificados especificadamente na acusação, mas que sofreram dano indiretamente terão direito de participar do processo. ${ }^{26}$ Por essa razão, o regramento desta matéria recebe diversas críticas.

Uma vez qualificada como vítima nos termos da regra $n^{\circ} 85$ do RPE, a Corte avaliará os requisitos para a participação estipulados no art. 68 (3) do Estatuto de Roma, examinando se existe interesse pessoal suficiente para a participação, e verificando se a mesma seria apropriada na fase processual em que esteja a causa, para que a inclusão da vítima como participante não seja prejudicial ou incompatível com os direitos do acusado a um julgamento equitativo e imparcial. ${ }^{27}$

No entanto, nem o Estatuto, nem as Regras de Procedimento e Provas dão detalhes substanciais acerca do conteúdo da participação das vítimas e de seu impacto no processo. Mesmo assim, pode-se afirmar que ela diferirá dependendo da fase do processo em que ocorrerá, eis que as modalidades de participação estão dentro do poder discricionário da respectiva câmara, que poderá adaptá-la de acordo com as circunstâncias específicas em julgamento. ${ }^{28}$

\footnotetext{
${ }^{26}$ SPIGA, Valentina. Indirect Victims' Participation in the Lubanga Trial. Journal of International Criminal Justice (Oxford University Press) Vol. 8, 2010, p. 186.

${ }_{27}$ BAUMGARTNER, Elisabeth. Aspects of Victim Participation in the Proceedings of the International Criminal Court. International Review of the Red Cross, v. 90, n 870, jun. 2008, p. 423.

${ }^{28}$ Ibid., p. 425.
} 
Cumpre lembrar que, embora não haja prescrição expressa sobre as modalidades de participação das vítimas, de acordo com o artigo 21 do Estatuto, a Corte deve aplicar, quando não houver resposta por parte do Estatuto ou do regulamento processual, os tratados, princípios e normas de direito internacional cabíveis. Desta forma, nas decisões relacionadas às vítimas, tem o Tribunal se referido à jurisprudência dos tribunais de direitos humanos, como a Corte Européia e a Interamericana de Direitos Humanos. Ademais, o TPI já usou também como fonte de inspiração nas suas decisões as Convenções da ONU, como a Convenção sobre os Direitos das Crianças, bem como a Declaração dos Princípios Básicos de Justiça relativos às vítimas da criminalidade e abuso de poder, e os Princípios Básicos e Diretrizes sobre o Direito à Reparação para Vítimas de Violação dos Direitos Humanos Internacionais e do Direito Humanitário. ${ }^{29}$

A participação é limitada no sentido de que não deve ser prejudicial ao processo nem incompatível com um julgamento justo, imparcial e rápido, mas, por outro lado, tem como característica a flexibilidade, tendo em vista sua adaptabilidade caso a caso. ${ }^{30}$

Deve-se notar que a sociedade civil tem papel importante também na fase pré-processual, mesmo antes de que seja formalmente admitida a participação no processo, pois para que iniciem-se as investigações por parte da Corte é necessária a existência de documentação, que eventualmente será proveniente das pessoas afetadas. ${ }^{31}$

De acordo com o Estatuto de Roma, as vítimas não tem capacidade para dar início a um inquérito, o que, entretanto, não impede que se possa afirmar que fornecendo ao Promotor informações relevantes, vítimas e Organizações não Governamentais possam ter um papel relevante no desencadeamento de uma investigação, estimulando e colocando certa pressão para que o procedimento investigatório se inicie. ${ }^{32}$

Fato é que, na verdade, esse direito de participação pode ser consistente com o sistema do tribunal, podendo as vítimas apontar e sugerir aos juízes como direcionar os seus poderes instrutórios (fact finding). Na realidade, o direito de levar provas não é apenas das partes. A câmara tem o direito geral de requisitar qualquer prova para determinar a verdade. $O$ direito de levá-las pertence originariamente às partes, que são a defesa e o procurador, cabendo a este último o ônus da prova. Mesmo assim, os redatores do Estatuto de Roma se atentaram ao fato que os juízes podem requisitar a submissão de todas as provas que puderem para chegar à verdade dos fatos, o que deixa aberta a possibilidade de que vítimas as submetam.

\footnotetext{
${ }^{29}$ ZEGVELD, Op. Cit., p. 101.

30 ZEGVELD, Loc. Cit.

31 Ibid., p. 426.

32 Ibid., p. 427.
} 
Sendo assim, as pessoas lesionadas poderão participar para garantir que o processo para o estabelecimento da verdade e a consequente absolvição ou condenação não envolva distorções dos fatos, o que faria com que as investigações não refletissem o que elas realmente sofreram. ${ }^{33}$

\section{DIFICULDADES PRÁTICAS}

Apesar de todos os aspectos positivos que representa, a aplicação pragmática do dispositivo relativo à participação das vítimas nos processos criminais em âmbito internacional é questão mais complicada que aparenta. Ademais, a expectativa que pode surgir diante de tal previsão pode quedar-se frustrada por diversos fatores.

Deve-se ressaltar que processos judiciais não têm objetivos terapêuticos. O julgamento do acusado se dará em razão dos fatos cometidos pelos perpetradores e da violação legal que praticaram os mesmos, e não pelo trauma sofrido subjetivamente. ${ }^{34}$ Neste contexto, alguns estudos apontam que existem lacunas entre o que as vítimas esperam e o que a Corte pode efetivamente oferecer.

O Tribunal Penal Internacional foi a primeira instância de julgamento que trouxe a modalidade de participação das vítimas nos moldes acima mencionados. Os tribunais ad hoc permitiam que as mesmas participassem tão somente como testemunhas, existindo algumas pesquisas que demonstram que, no Tribunal ad hoc para a lugoslávia, por exemplo, as vítimas ficam insatisfeitas como o seu pape ${ }^{35}$, acabando a experiência por caracterizar-se como uma vitimização secundária, pois muitas vezes o tratamento recebido por elas não correspondia ao esperado, além do fato de o procedimento as fazer relembrar as experiências traumáticas do passado, de modo que as mesmas sofressem novamente com os questionamentos a que eram submetidas. ${ }^{36}$

Ademais, o curto espaço de tempo que de que dispunham os juízes para a oitiva impunha restrições quanto à narrativa proporcionada pelas vítimas, o que poderia acabar por fazer surgir o sentimento de negativa do sofrimento das mesmas ${ }^{37}$, considerando que seus depoimentos em algumas ocasiões eram cortados para que apenas o que fosse relevante para a verificação da culpa do acusado viesse à tona. ${ }^{38}$ Assim, não havia espaço para emoção,

\footnotetext{
33 ZAPPALÀ, Op. Cit., p. 161.

${ }^{34}$ RAUSCHENBACH, Mina. et. al. Victims and International Criminal Justice: a vexed question? International Review of Red Cross. Cambridge Journals, v. 90, nº 870, jun. 2008, p. 449.

${ }^{35}$ WEMMERS, Jo-Anne. Victim's Rights and the International Criminal Court: Perceptions within the Court Regarding the Victims Right to Participate. Leiden Journal of International Law. Cambridge Journals, v. 23, 2010, p. 640.

${ }^{36}$ Idem, p. 444.

${ }^{37}$ DEMBOUR, Marie-Bénédicte et. al. Silencing Hearings? Victim-Witnesses at War Crimes Trials. European Journal of International Law. V. 15, n 1, 2004, p. 175.

${ }^{38}$ Ibid., p. 158.
} 
pois o tribunal não estava lá para dividir a dor, não sendo um espaço para afligir $^{39}$, devendo a produção das provas acontecer de maneira objetiva. ${ }^{40}$

Além disso, as vítimas eram convidadas à reconciliação e perdão sem que houvesse preparação para tanto, o que fazia com que todo o contexto de testemunho nesse tribunal acabasse por se tornar um procedimento danoso para aquelas pessoas em termos gerais ${ }^{41}$.

Desta forma, esta nova modalidade de participação inserida no artigo 68 (3) do Estatuto de Roma acabou por trazer expectativas à sociedade civil, pois esta ferramenta poderia dar, em tese, maior reconhecimento ao seu sofrimento. Entende-se modernamente que os procedimentos criminais não devem mais apenas preocupar-se com punição, mas também em por fim ao sofrimento e em ajudar as vítimas a reconstruir suas vidas ${ }^{42}$, o que não se confunde a dar ao processo penal a função de cura. Este dispositivo, portanto, foi visto como uma potencial fonte de auxílio às pessoas afetadas.

Segundo estudos desenvolvidos sobre o tema, as principais expectativas das vítimas quando participantes de processos judiciais são: ter suas vozes ouvidas; participar da instrução do caso; ser tratadas com respeito e justiça; ter informações acerca do caso e de seu progresso; obter indenização em termos econômicos e emocionais ${ }^{43}$.

Destarte, percebe-se que muitas vezes o que mais importará não é a punição em si do perpetrador, mas todo o contexto de atenção e reconhecimento do sofrimento das vítimas, pois retribuição talvez não seja tão importante quanto geralmente se pensa ${ }^{44}$, considerando que nos dias de hoje entende-se que um sistema baseado em retribuição apenas conduz à intensificação dos conflitos. ${ }^{45}$ Assim, a lógica da participação das vítimas visa alcançar uma justiça restaurativa, em nítido contraste com objetivos meramente retributivos. ${ }^{46}$

Contudo, como acima mencionado, existem pesquisas que demonstram que existem lacunas entre a expectativa que gira em torno da previsão disposta no art. 68 (3) e o que a Corte pode oferecer em termos práticos, em razão de algumas dificuldades que se fazem presentes.

Dentre tais dificuldades, pode ser citada a distância existente entre o Tribunal Penal Internacional e as comunidades afetadas. Muitas vítimas até mesmo desconhecem a existência da Corte, ou não acreditam na efetividade de julgamento. Em entrevistas realizadas, algumas vítimas comentam "It's a dream. . . . Is it true that the ICC will do a trial for me? I don't think so.

\footnotetext{
39 Ibid., p. 159.

40 lbid., p. 164.

${ }^{41}$ Ibid., p. 172.

${ }^{42}$ RAUSCHENBACH, Op. Cit., p. 443.

${ }^{43}$ STRANG, Heater, apud RAUSCHENBACH, Op. Cit., p. 444.

${ }^{44}$ Erez et. al, apud RAUSCHENBACH, Loc. Cit.

${ }^{45}$ RAUSCHENBACH, Op. Cit., p. 448.

${ }^{46}$ SPIGA, Op. Cit., p. 189.
} 
Because the white people always come to collect testimonies and they go. . . . But I pray God that the rape trial really occurs. ${ }^{, 47}$

Outros, quando indagados sobre a vontade de participar no julgamento respondem que: "We will have to first touch the ICC, to touch his representative here". ${ }^{48}$ Da distância decorre outra dificuldade, qual seja a falta de divulgação de informações. Informação e notificação sobre os atos processuais são importantes, pois significa para as vítimas que não estão esquecidas, e que seus interesses no caso são reconhecidos. Vítimas que são informadas sobre seus direitos e notificadas do desenvolvimento da situação tendem a ficar mais satisfeitas com o sistema judicial e a sentir que estão sendo tratadas de forma justa. ${ }^{49}$ Além disso, o acesso à informação é uma garantia para elas, que querem saber a verdade sobre os fatos. A verdade, que não é uma conveniência política, mas um imperativo, pode ajudar a fornecer um registro histórico, educar as pessoas, promover o perdão e prevenir a vitimização.

No entanto, a Corte não se comunica diretamente com as vítimas, mas com seus representantes legais. Como resultado, não há contato direto com as mesmas e esse órgão: todas as comunicações passam pelos advogados. Isto é uma particularidade importante, na medida em que muda a característica da participação delas no processo, pois ter um advogado que fala em seus nomes muda o discurso de apelos emotivos para argumentos legais. ${ }^{51}$ Desta forma, os advogados poderão trazer os pontos de vista das vítimas e mostrar suas preocupações sobre as questões jurídicas em discussão. ${ }^{52}$

Apesar disso, uma das maiores críticas que se faz continua sendo a falta de divulgação sobre a Corte para os territórios em que são cometidas as atrocidades, pois em algumas localidades o Tribunal Penal Internacional ainda não se fez conhecido. Além do mais, existem lugares onde há certa hostilidade por parte das populações investigadas. ${ }^{53}$ Assim, percebe-se que boa parte das pessoas afetadas não são familiarizadas com o TPI. Traumatizadas pelos conflitos pois eram os alvos principais, e negligenciadas pelo sistema jurídico disfuncional em âmbito nacional, não se pode esperar que tais indivíduos compreendam as intenções da Corte, quanto mais seus procedimentos e limitações sem que haja esforço para que isso Ihes seja explicado. ${ }^{54}$

\footnotetext{
47 "é um sonho... é verdade que o Tribunal Penal Internacional vai realizar um julgamento por mim? Eu acho que não. Porque as pessoas brancas sempre vem coletar depoimentos e se vão... Mas eu rezo à Deus que o julgamento do estupro realmente aconteça" in GLASIUS, Marlies. Global Justice Meets Local Civil Society: The International Criminal Court's Investigation in the Central African Republic. Alternatives, 33, 2008, p. 421 (tradução dos autores).

48 "Primeiro, temos que ter contato com o Tribunal Penal Internacional, ter seu representante aqui". GLASIUS, Loc. cit. (tradução dos autores).

${ }^{49}$ WEMMERS, Jo-Anne. Op. Cit., p. 641.

${ }^{50}$ BASSIOUNI, Op. Cit., p. 275.

${ }^{51}$ WEMMERS, Loc. Cit.

${ }^{52}$ Ibid, p. 643.

${ }^{53}$ GLASIUS, Op. Cit., p. 510

${ }^{54}$ Ibid, p. 511.
} 
Na busca de que fosse sanada a falta de proximidade entre a Corte e as vítimas foi aberto em outubro de 2007, na República Centro Africana, um escritório em que foram realizados vários workshops para jornalistas, advogados, grupos de vítimas e líderes religiosos. Todavia, tendo em vista que não foi montada nenhuma equipe permanente, a divulgação se deu de forma esporádica. Sendo assim, para suprir o alcance esperado, várias ONGs locais e internacionais tem se encarregado de fazer sua própria divulgação, informando as populações locais sobre as investigações do Tribunal e, mais particularmente sobre a possibilidade legal de participar em um Tribunal com capacidade processual. ${ }^{55}$

Destarte, o Tribunal conta com pequenos grupos da sociedade civil para fazer divulgações, bem como para coletar provas e encontrar vítimas e testemunhas dispostas a depor. Estes grupos são, por sua vez, dependentes do tribunal para fazer cumprir suas aspirações para o julgamento em busca de justiça, que certamente não aconteceria brevemente em níveis nacionais. A situação não é a ideal, mas considerando a disfunção estrutural dos Estados em que acontecem as atrocidades que serão julgadas, talvez seja a versão mais adequada de justiça em oferta. ${ }^{56}$

Outra dificuldade também relacionada ao contexto da área em que os crimes acontecem, é relativamente à própria dificuldade de sobrevivência das pessoas que moram nas localidades, não em razão da condição de serem vítimas dos crimes sob julgamento, mas em decorrência da ausência de infraestrutura dos países. Muitas vezes as vítimas não se importam tanto com o julgamento em si, pois as mesmas têm necessidades básicas com as quais se preocupar.

Neste contexto, embora teoricamente tenham vontade de participar do julgamento na Corte, expressam primeiramente a preocupação em como irão sobreviver, pois necessitam de comida, medicamentos e de maneiras de buscar provimentos. De acordo com uma vítima infectada pelo HIV da República Centro Africana:

"It's true that I want a trial. But they should at least bring little things so that I can eat. Because I am sick. I need to have strength to continue to wait. And we also want to do little activities that bring us more income to survive. ${ }^{57}$

\footnotetext{
${ }^{55}$ GLASIUS, Loc. Cit.

${ }^{56}$ GLASIUS, Marlies. Global Justice Meets Local Civil Society: The International Criminal Court's Investigation in the Central African Republic. Alternatives, v. 33, 2008, p. 428.

57 "É verdade que eu quero um julgamento. Mas eles devem, pelo menos, trazer coisas que eu possa comer. Porque eu estou doente. Eu preciso ter forças para continuar a esperar. E nós também queremos ter atividades que possam nos trazer renda para sobreviver." in GLASIUS, Op. Cit., p. 418 (tradução dos autores).
} 
Além das falhas apontadas, ainda existe aquela concernente ao tempo do processo. Segundo alguns estudiosos, na República Democrática do Congo, por exemplo, o ritmo da Corte foi a maior fonte de ansiedade e decepção para as figuras da sociedade civil e para as vítimas. ${ }^{58} \mathrm{Em}$ âmbito nacional a demora nos processos geralmente se configura como um problema, mas isto é ainda mais grave quando se trata de crimes internacionais, pois seus mecanismos judiciais são lentos e dependentes de fatores econômicos e políticos. ${ }^{59}$ Portanto, o tempo das necessidades das vítimas dificilmente coincidirá com o tempo judicial.

Não bastassem as dificuldades supramencionadas, deve ser ressaltada ainda a possibilidade de frustração oriunda da característica de seletividade que possui o Tribunal Penal Internacional. Em razão disso, serão julgados pela Corte apenas os criminosos com "maior responsabilidade", sendo os demais casos analisados pelas cortes nacionais. ${ }^{60}$ Isto pode fazer com que 0 Tribunal pareça fraco e irrelevante com relação aos conflitos acontecidos nas localidades afetadas ${ }^{61}$, pois as vítimas podem continuar se sentindo inseguras se aqueles que diretamente lhe provocaram mal continuarem livres.

Assim, pode parecer que a justiça proporcionada pelo Tribunal Penal Internacional é incompleta, pois apenas o "peixe grande" é capturado, enquanto pode acontecer que os soldados diretamente responsáveis pelos crimes continuem impunes. ${ }^{62}$ Por isto, outra grande crítica que se faz é quanto à estreiteza do julgamento proporcionado pela Corte.

Por outro lado, deve-se reconhecer que o Tribunal não é capaz de sozinho acabar com a impunidade. Ademais, segundo palavras de uma vítima da República Centro Africana: "If they arrest the highest it's still good. . . They will still have helped us. If the big fish stay, who have killed, they recruit others and train them again." ${ }^{63}$

Mesmo frente todas as dificuldades aqui referidas, existem vítimas motivadas a participar dos processos correntes no Tribunal Penal Internacional, seja por indignação pelas atrocidades cometidas e por anseios de punição, seja por perspectivas econômicas. ${ }^{64}$

Porém, diante do exposto percebe-se que o mecanismo previsto no art. 68 (3) do Estatuto de Roma pode não ser o mais adequado para preencher as expectativas das pessoas afetadas. Talvez essa disposição não esteja ao alcance do que é esperado pelas vítimas, tendo em vista que elas necessitam

\footnotetext{
${ }^{58}$ GLASIUS, Op. Cit, p. 512.

${ }^{59}$ RAUSCHENBACH, Op. Cit., p. 452.

${ }^{60}$ GLASIUS, Op. Cit., p. 513.

61 Ibid, p. 503.

62 Ibid, p. 502.

63 "Se eles só prenderam o maior, ainda é bom... Eles já nos ajudaram. Se o peixe grande permanece, recruta outros e os treina para matar de novo" in GLASIUS, Op. Cit., p. 419.

64 Ibid., p. 423.
} 
de um atendimento integral, e a participação no processo, como acima explanado, é uma ferramenta que na verdade será manuseada pelos advogados das mesmas, de modo a contribuir com a instrução do processo e não com a cura dos traumas sofridos, pois processos judiciais dificilmente alcançam este resultado.

É verdade que a participação pode dar a impressão de que justiça está sendo feita, e de que as vítimas estão sendo respeitadas e tendo seus interesses atendidos. Entretanto, é preciso mais do que isto. Nesta conjuntura, alguns estudos apontam que vítimas que tem apoio do círculo social em que estão inseridas são aquelas que têm experiências mais positivas, pois a cura não vem dos procedimentos criminais em si. ${ }^{65}$

É preciso então que se crie uma cultura não de retributividade, mas sim de busca da justiça restaurativa, para que a todas as partes de uma ofensa juntas busquem coletivamente lidar com as consequências do delito e com suas implicações no futuro ${ }^{66}$.

Deve-se ressaltar que, a bem da verdade, é necessário que haja uma composição entre diferentes olhares e formas de intervenção, pois a resposta formal de instâncias jurídicas não é suficiente para o rompimento do ciclo de violência, mostrando-se imprescindível uma atuação interdisciplinar e integral de atenção a vítima. Em um atendimento interdisciplinar e integral com perspectiva de direitos humanos, o olhar e a interação com a vítima considera a história de vida e a possibilidade de mudanças e de transformação do sujeito. Daí surge a necessidade de diálogo e interação entre os diferentes profissionais e áreas do saber. ${ }^{67}$

Sendo assim, a exposição de preocupações e pontos de vista no processo no Tribunal Penal Internacional por meio de advogado pode colaborar para com a situação das vítimas, para tirar-lhes da situação de passividade de mera recepção de favores, de modo que as mesmas possam ter um papel ativo no julgamento, mas não é, no entanto, um instrumento suficiente para ajudá-las em seu processo de cura.

Neste ínterim, existe uma ferramenta também prevista pelo Estatuto de Roma que pode ser útil, consubstanciada no artigo 75 , que dispõe sobre os mecanismos de indenização pelos danos sofridos. O Tribunal Penal Internacional pode, deste modo, conceder indenização individual ou coletiva, para um grupo de vítimas ou de uma comunidade. Se decidir pela reparação coletiva, pode ordenar que ela se dê por meio do Trust Fund, que pode ser paga para uma organização nacional, intergovernamental ou internacional. ${ }^{68}$

\footnotetext{
${ }^{65}$ RAUSCHENBACH, Op. Cit., p. 448.

${ }^{66}$ Ibid., p. 457.

${ }^{67}$ KAMIMURA, Akemi. A Efetivação dos Direitos Humanos: o desafio do direito no atendimento interdisciplinar a vítimas de violência. 2009. 191 f. Dissertação (Mestrado em Direito) - Faculdade de Direito - Universidade de São Paulo, São Paulo, 2009, p. 45.

${ }^{68}$ ZEGVELD, Op. Cit., p. 98.
} 
Frente à dificuldade de indenizar individualmente, o Trust Fund passa a ser a melhor opção ${ }^{69}$, se mostrando esta previsão um componente importante para o processo de justiça restaurativa. ${ }^{70}$

Cumpre lembrar que no processo de reparação, a participação das vítimas poderá acontecer de forma mais abrangente, tendo em vista que o procedimento para a determinação da indenização ocorre em momento posterior à condenação. ${ }^{71}$

Estes procedimentos se justificam pois os processos criminais da justiça internacional não devem apenas punir, são mais amplos e devem compreender a reabilitação das vítimas, assumindo um papel pedagógico envolvendo as comunidades afetadas. ${ }^{72}$ Sendo assim, o aspecto da reparação material, além da imaterial satisfação pelo julgamento não pode ser negligenciado. ${ }^{73}$ Para melhor lidar com essas questões, já se fala até que o ideal seria a criação de uma Corte Internacional Civil. ${ }^{74}$

\section{JUSTIÇA DE TRANSIÇÃO}

Neste contexto de busca de formas alternativas de justiça, que não só a justiça punitiva, entra em cenário a chamada justiça de transição. Em suma, ela alude ao conjunto de medidas judiciais e extrajudiciais implementadas por alguns países para amenizar o legado deixado pelos grandes abusos de direitos humanos. Não se trata de um tipo especial de justiça, mas é uma abordagem para alcançá-la na situação de transição de conflitos ou repressão dos Estados autoritários, pois se busca a responsabilização e o reconhecimento do direitos das vítimas, de modo a contribuir para o fortalecimento do Estado Democrático de Direito. ${ }^{75}$

Tais medidas podem ser de vários matizes pois não há uma regra geral para a aplicação de uma justiça de transição. Todavia, existem elementos tidos como essenciais que são: os processos criminais, para que sejam investigados os responsáveis pelos crimes; os programas de reparação patrocinados pelo Estado, para contribuir com as consequências materiais e morais dos abusos sofridos pelas vítimas; a reforma institucional das instituições estatais relacionadas com a repressão, para manter a integridade do serviço público; as comissões de verdade, relacionadas à iniciativa de proporcionar a verdade às pessoas afetadas. ${ }^{76}$ Este rol, no entanto, não é taxativo, tendo em vista

\footnotetext{
${ }^{69}$ Ibid, p. 89.

${ }^{70}$ BASSIOUNI, Op. Cit., p. 231.

${ }^{71}$ BAUMGARTNER, Op. Cit., p. 432.

${ }^{72}$ ZAPPALÀ, Op. Cit., p. 163.

${ }^{73}$ BAUMGARTNER, Op. Cit., p. 438.

${ }^{74}$ ZEGVELD, Op. Cit, p. 111.

75 INTERNATIONAL CENTER FOR TRANSITIONAL JUSTICE. What is Transitional Justice? Disponível em: <http://ictj.org/about/transitional-justice > Acesso em 03 nov. 2011.

${ }^{76}$ UNITED NATIONS. WHAT IS TRANSITIONAL JUSTICE? A backgrounder. Disponível em <http://www.un.org/peace/peacebuilding/Working\%20Group\%20on\%20Lessons\%20Learned/Justice \%20in\%20Times\%20of\%20Transition\%20\%2826.02.2008\%29/26.02.2008\%20\%20Background\% 20note.pdf> Acesso em 03 nov. 2011.
} 
que várias outras medidas podem ser implementadas, como a criação de museus, memoriais e outras iniciativas simbólicas. ${ }^{77}$

Este tipo de abordagem faz-se importante nos processos de pacificação de conflitos na medida em que as violações sistemáticas de direitos humanos não afetam apenas as vítimas diretas, mas a sociedade como um todo, tendo o Estado, neste panorama, um dever especial de garantir que as violações não se repitam e de reformar as instituições que eram responsáveis ou incapazes de impedir os abusos. ${ }^{78}$

Sendo assim, aponta-se que são quatro os deveres impostos aos Estados para a transformação política ao fim de um período de repressão ou conflito armado, que são 1) a investigação, processamento e punição dos violadores dos direitos humanos; 2) a revelação da verdade para as vítimas, seus familiares, bem como para toda a sociedade; 3) oferecimento de reparação adequada; 4) afastamento dos criminosos de órgãos relacionados ao exercício da lei e outras posições de autoridade ${ }^{79}$.

Esta forma de abordagem reconhece que existem dois objetivos para lidar com o legado histórico deixado pelos abusos massivos de direitos humanos. O primeiro é relativo às vítimas, reconhecendo a necessidade de oferecimento de justiça às mesmas. O segundo é o reforço das possibilidades de paz, reconciliação e democracia. Por não ser tarefa fácil, é necessário dar a tais medidas um olhar holístico, pelo qual se deve combinar elementos da justiça criminal, restaurativa e social, adaptando-se tais elementos de acordo com as condições das sociedades em transformação. ${ }^{80}$

A recente condenação de Thomas Lubanga Dyilo pelo recrutamento de crianças-soldado durante a guerra civil na República Democrática do Congo demonstra como a participação das vítimas no procedimento criminal deve seguir-se a adoção de medidas relativas à Justiça de Transição. O direito das vítimas à reparação foi reconhecido pela Assembleia das Nações Unidas pela Resolução sobre Princípios Básicos e Diretrizes sobre o Direito e as medidas de Reparação à Vítimas. ${ }^{81}$ Considerado um marco inicial para o tratamento da

\footnotetext{
77 INTERNATIONAL CENTER FOR TRANSITIONAL JUSTICE. What is Transitional Justice? Disponível em: <http://ictj.org/about/transitional-justice > Acesso em 03 nov. 2011.

78 INTERNATIONAL CENTER FOR TRANSITIONAL JUSTICE. What is Transitional Justice? Disponível em: <http://ictj.org/about/transitional-justice > Acesso em 03 nov. 2011.

${ }_{79}$ MEZAROBBA, Glenda. "Não existe programa de reparação que tenha conseguido compensar as vítimas na proporção do dano sofrido". Jornal da Unicamp. Campinas, 3-9 Nov. 2008, p. 09, disponível em <http://www.unicamp.br/unicamp/unicamp_hoje/ju/novembro2008/ju415pdf/Pag09.pdf> Acesso em 03 nov. 2011.

${ }^{80}$ UNITED NATIONS. WHAT IS TRANSITIONAL JUSTICE? A backgrounder. Disponível em $<$ http://www.un.org/peace/peacebuilding/Working\%20Group\%20on\%20Lessons\%20Learned/Justice \%20in\%20Times\%20of\%20Transition\%20\%2826.02.2008\%29/26.02.2008\%20\%20Background\% 20note.pdf> Acesso em 03 nov. 2011.

${ }^{81}$ UN GENERAL ASSEMBLY. Basic Principles and Guidelines on the Right to a Remedy and Reparations for Victims of Gross Violations of International Human Rights Law and Serious Violations of International Humanitarian Law: resolution adopted by the UN General Assembly in
} 
matéria pelo Tribunal Penal Internacional, o Caso Lubanga poderá trazer respostas a questões importantes como quem tem direito às medidas de reparação, como esta reparação aconteceria e como as vítimas poderão influir nas ações do Tribunal voltadas a essa finalidade. ${ }^{82}$

A definição das vítimas é fundamental para se mensurar a extensão e se definir o escopo das medidas de reparação, compensação e reabilitação a serem adotadas. Se forem consideradas vítimas apenas àqueles indivíduos diretamente referidos como tais no procedimento judicial apenas uma porção muito pequena das pessoas atingidas pelos crimes de Lubanga seria beneficiada. As vítimas seriam apenas as crianças-soldado do grupo étnico de Lubanga, os Hema. Estariam excluídas as pessoas que sofreram com os assassinatos, mutilações, pilhagem e estupros cometidos pela milícia de Lubanga, cujo alvo preferencial era a etnia Lendu ${ }^{83}$. Estariam excluídas também as crianças-soldado que foram recrutadas antes de julho de 2002 (marco inicial da competência temporal do Tribunal Penal Internacional sobre o caso) embora o conflito na República Democrática do Congo tenha se iniciado em $1993 .{ }^{84}$ Também estariam excluídas da condição de vítima as meninas que foram aprisionadas para servirem de escravas sexuais para a milícia porque Lubanga não foi condenado por crimes de gênero, muito embora tenham sido ouvidos relatos de sua ocorrência no procedimento. ${ }^{85}$

Definir a natureza das medidas de reparação é outro assunto fundamental para as vítimas. Algumas ações tem sido tomadas por organizações humanitárias com vistas à reintegração das crianças-soldado na sociedade, mas sua eficácia tem sido objeto de discussão. Os programas financiam apenas um ano de estudo às ex-crianças soldado ou, quando fornecem cursos profissionalizantes, formam 20 carpinteiros para uma aldeia com poucas centenas de habitantes ou, ainda, fornecem um bode para que cada vítima tenha meios econômicos de manter-se. ${ }^{86}$ Embora o Estatuto de Roma não disponha sobre a natureza das medidas de reparação os Tribunais Ad Hoc da ONU e o Tribunal Misto do Cambodja pagou indenizações em dinheiro para as vítimas. ${ }^{87}$ No caso Lubanga, entretanto, especialistas defendem que as medidas de reparação devem ser coletivas, através de programas visando

\footnotetext{
December 2005 published on 21 March 2006, A/RES/60/147. Disponível em <www.unhcr.org/ refworld/docid/4721cb942.html>. Acesso em 22 abr. 2012.

${ }^{82}$ CARRANZA, Ruben. Reparations and the Lubanga Case: learning from transitional justice. New York: International Centre for Transitional Justice, April 2012. Disponível em <www.ictj.org>. Acesso em 02 maio 2012, p. 1.

${ }^{83}$ EVANS-PRITCHARD, Blake; GOUBY, Mélanie. Lubanga Verdict Prompts Debate on Reparations. Disponível em <http://iwpr.net/report-news>. Acesso em 03 maio 2012, p. 3.

${ }^{84}$ CARRANZA, Ruben, Op. Cit., p. 2.

${ }^{85}$ THE WOMEN'S INITIATIVES FOR GENDER JUSTICE. Women's Initiatives for Gender Justice Observations on Reparations. ICC-01/04-01/06, 10 May 2002, p. 7 e 8.

${ }^{86}$ EVANS-PRITCHARD, Blake; GOUBY, Mélanie, Op. Cit., p. 1 e 3.

${ }^{87}$ CARRANZA, Ruben, Op. Cit., p. 2.
} 
a melhoria da qualidade de vida das comunidades afetadas e não por ações que resultem em benefício individual direto das vítimas. ${ }^{88}$

A adoção de programas de reparação coletiva indica também a necessidade das pessoas afetadas pelos crimes participarem e opinarem sobre o procedimento de reparação da mesma forma que as vítimas participaram do procedimento criminal. O International Center for Transitional Justice sugere, por exemplo, a criação de memoriais em honra das vítimas e de um centro de documentação histórica para servir de referências a futuras gerações. ${ }^{89}$ Outra observação feita pela doutrina é que nos programas deve-se ficar claro que se trata de uma medida de reparação ao sofrimento das vítimas e buscar-se promover a reconciliação entre as diferentes etnias, diferenciando-se, assim, de uma ação humanitária. ${ }^{90}$

Deste modo, o Caso Lubanga demonstra que, para as medidas de reparação do Tribunal Penal Internacional serem bem sucedidas é necessária uma definição de vítima que inclua todos os membros afetados pelos crimes e não apenas aqueles diretamente relacionados à condenação criminal. Tal definição, juntamente com a noção de medidas de reparação coletiva, planejadas em conjunto com as comunidades atingidas, pode tornar a participação das vítimas no procedimento criminal e a posterior reparação de seu sofrimento uma matéria bastante para o Tribunal.

\section{CONSIDERAÇÕES FINAIS}

O objetivo deste trabalho foi analisar a participação das vítimas nos procedimentos criminais do Tribunal Penal Internacional. Para tanto, em breves noções acerca da instituição, percebeu-se que sua entrada em funcionamento significou algumas alterações para o Direito Internacional, dentre elas a consolidação do papel do indivíduo como Sujeito de Direito Internacional. Corolário de uma nova ordem internacional na qual a sociedade de Estados convive com uma sociedade civil, em um espaço público internacional, a personalidade jurídica internacional do indivíduo permite vítimas participem no polo ativo de um procedimento criminal ao lado da Procuradoria.

O instituto da participação das vítimas, contudo, encontra-se regulamentado de forma vaga, tanto no Estatuto de Roma quanto nas Regras de Procedimento e Evidência do Tribunal. Tal vagueza das disposições responde parcialmente pelo fato de que a efetivação do direito de participação das vítimas no procedimento encontra uma série de dificuldades práticas.

Além disso, as expectativas das vítimas pelo reconhecimento de seu sofrimento, além de medidas de reparação, encaminham as atividades do Tribunal em direção a um contexto mais amplo, com a aplicação dos postulados da Justiça de Transição, como se depreende da análise do Caso Lubanga.

\footnotetext{
${ }^{88}$ EVANS-PRITCHAR, Blake; GOUBY, Mélanie, Op. Cit, p. 2.

${ }^{89}$ CARRANZA, Ruben, Op. Cit., p. 2.

${ }^{90}$ EVANS-PRITCHAR, Blake; GOUBY, Mélanie, Op. Cit, p. 3.
} 
Em síntese, pode-se afirmar que a participação das vítimas nos procedimentos criminais do Tribunal Penal Internacional é importante fator para a consolidação da personalidade jurídica internacional do indivíduo e auxilia o Tribunal a se aproximar das comunidades atingidas pelos crimes que julga. Todavia, o atendimento às expectativas das vítimas em relação ao procedimento em si e às medidas de reparação não parece estar ao alcance do Tribunal, a não ser em um contexto mais amplo em que os julgamentos sejam parte de uma justiça de transição vivenciada por toda a sociedade.

\section{REFERÊNCIAS}

BASSIOUNI, M. Cherif, International Recognition of Victims' Rights. Human Rights Law Review. Oxford University Press, v. 6, n 2, p. 203-279, 2006.

BAUMGARTNER, Elisabeth. Aspects of Victim Participation in the Proceedings of the International Criminal Court. International Review of the Red Cross, v. 90, $\mathrm{n}^{\circ} 870$, p. 409-440, jun. 2008.

CARRANZA, Ruben. Reparations and the Lubanga Case: learning from transitional justice. New York: International Centre for Transitional Justice, April 2012. Disponível em <www.ictj.org >. Acesso em 02 maio 2012.

COALITION FOR THE INTERNATIONAL CRIMINAL COURT. About The Coalition. Disponível em: <www.iccnow.org>. Acesso em: 18 out. 2011.

DEMBOUR, Marie-Bénédicte et. al. Silencing Hearings? Victim-Witnesses at War Crimes Trials. European Journal of International Law. V. 15, nº 1, p. 151-177, 2004.

EVANS-PRITCHARD, Blake; GOUBY, Mélanie. Lubanga Verdict Prompts Debate on Reparations. Disponível em <http://iwpr.net/report-news>. Acesso em 03 maio 2012.

FRIMAN, Hãkan. The International Criminal Court and Participation of Victims: A Third Party to the proceedings? Leiden Journal of International Law (Foundation of the Leiden Journal of international Law), vol. 22, p. 485-500, 2009.

GLASIUS, Marlies. Global Justice Meets Local Civil Society: The International Criminal Court's Investigation in the Central African Republic. Alternatives, 33, p. 413-433, 2008.

What is Global Justice and Who Decides? Civil Society and Victim Responses to the International Criminal Court's First Investigations. Human Rights Quarterly, The Johns Hopkins University Press, v. 31, nº 2, p. 496-520, maio 2009.

INTERNATIONAL CENTER FOR TRANSITIONAL JUSTICE. What is Transitional Justice? Disponível em: <http://ictj.org/about/transitional-justice> Acesso em 03 nov. 2011.

INTERNATIONAL CRIMINAL COURT - The States Parties to the Rome Statute. Disponível em: <http://www.icc cpi.int/Menus/ASP/states+parties/> Acesso em 03 nov. 2011.

JOSEPH, Joshua H. Gender and International Law: How the Internacional Criminal Court can bring justice to victims of sexual violence. Texas Journal of Women and the Law (University of Texas at Austin School of Law Publications) Vol. 18:61, p. 61-101, 2008.

KAMIMURA, Akemi. A Efetivação dos Direitos Humanos: o desafio do direito no atendimento interdisciplinar a vítimas de violência. 2009. 191 f. Dissertação (Mestrado em Direito) - Faculdade de Direito - Universidade de São Paulo, São Paulo, 2009.

LIMA, Renata Mantovani de; BRINA, Marina Martins da Costa. Para Entender o Tribunal Penal Internacional. Belo Horizonte: Del Rey, 2006. 
MAIA, Marrielle. Tribunal Penal Internacional: aspectos institucionais, jurisdição e princípio da complementaridade. Belo Horizonte: Del Rey, 2001.

MEZAROBBA, Glenda. "Não existe programa de reparação que tenha conseguido compensar as vítimas na proporção do dano sofrido". Jornal da Unicamp. Campinas, 3-9 Nov. 2008, p. 09, disponível em:

<http://www.unicamp.br/unicamp/unicamp_hoje/ju/novembro2008/ju415pdf/Pag09.pdf> Acesso 03 nov. 2011.

MIRANDA, João Irineu de Resende. O Tribunal Penal Internacional frente ao Princípio da Soberania. Londrina: Eduel, 2011.

PIOVESAN, Flávia. Direitos Humanos e Justiça Internacional: um estudo comparado dos sistemas regionais europeu, interamericano e africano. São Paulo: Saraiva, 2006.

RAUSCHENBACH, Mina. et. al. Victims and International Criminal Justice: a vexed question? International Review of Red Cross. Cambridge Journals, v. 90, $\mathrm{n}^{\circ} 870$, p. 441- 459, jun. 2008.

SPIGA, Valentina. Indirect Victims' Participation in the Lubanga Trial. Journal of International Criminal Justice (Oxford University Press) Vol. 8, p. 183-198, 2010.

THE WOMEN'S INITIATIVES FOR GENDER JUSTICE. Women's Initiatives for Gender Justice Observations on Reparations. ICC-01/04-01/06, 10 May 2002.

UN GENERAL ASSEMBLY. Basic Principles and Guidelines on the Right to a Remedy and Reparations for Victims of Gross Violations of International Human Rights Law and Serious Violations of International Humanitarian Law: resolution adopted by the UN General Assembly in December 2005 published on 21 March 2006, A/RES/60/147. Disponível em <www.unhcr.org/refworld/docid/4721cb942.html>. Acesso em 22 abr. 2012.

UNITED NATIONS. WHAT IS TRANSITIONAL JUSTICE? A backgrounder. Disponível em <http://www.un.org/peace/peacebuilding/Working\%20Group\%20on\%20Lessons\%20 Learned/Justice\%20in\%20Times\%20of\%20Transition\%20\%2826.02.2008\%29/26.02.2008 \%20\%20Background\%20note.pdf> Acesso em 03 nov. 2011.

VYVER, Johan D. Van Der. Civil Society and the International Criminal Court. Journal of Human Rights, vol. 2, n 3, p. 425-439, set. 2003.

WEMMERS, Jo-Anne. Victim's Rights and the International Criminal Court: Perceptions within the Court Regarding the Victims Right to Participate. Leiden Journal of International Law. Cambridge Journals, v. 23, p. 629-643, 2010.

ZAPPALÀ, Salvatore. The Rights of Victims v. the Rights of the Accused. Journal of International Criminal Justice (Oxford University Press) Vol. 8, p. 137-164, 2010.

ZEGVELD, Liesbeth. Victims' Reparations Claims and International Criminal CourtIncompatibleValues? Journal of International Criminal Justice, Oxford University Press, v. 8, p. 79-111, 2010. 